\title{
Effect of straw and polyacrylamide on the stability of land/water ecotone soil and the field implementation
}

\author{
Shaoyong $\mathrm{Lu}^{\mathrm{a}}$, Fangxin Chen ${ }^{\mathrm{a}, *}$, Huu Hao Ngo ${ }^{\mathrm{b}}$, Wenshan Guo ${ }^{\mathrm{b}}$, Chuanping Feng ${ }^{\mathrm{c}}$, Jinan Wu ${ }^{\mathrm{a}}$, Binghui \\ Zheng $^{\mathrm{a}, *}$
}

\author{
a State Environmental Protection Key Laboratory for Lake Pollution Control, Research Centre of Lake Environment, Engineering and \\ Technology Centre of Lake, Chinese Research Academy of Environmental Sciences, Beijing 100012, China \\ b School of Civil and Environmental Engineering, University of Technology Sydney, Broadway, NSW 2007, Australia \\ c China Unversity of Geosciences, Institute of water resources and the environment, Beijing 100012, China \\ * Corresponding authors. E-mail addresses: lushy2000@163.com (S. Lu), chenfx@cugb.edu.cn (F. Chen)
}

\begin{abstract}
Poor stability of land/water ecotone (L/WE) soil is a serious and increasing problem in the context of ecological restoration. Effective management by adding straw and polyacrylamide (PAM), i.e., SPAM, to soil may increase soil stability, including structure and fertility. Thus, it is important to explore the effects of SPAM on L/WE soil, as well as to determine the appropriate ratio of straw and PAM to achieve optimal increases. To investigate the soil properties and provide basis for ecological restoration, an indoor soil culture experiment, including nine straw and PAM combinations, was conducted. It was found that $3 \mathrm{~g} / \mathrm{kg}$ straw with $1 \mathrm{~g} / \mathrm{kg}$ PAM was optimal; thus, this scale was applied in engineering of Gonghu L/WE, which was turning Fishery to Lake. The survey explored changes in soil nutrients and structure, dry-sieved aggregate stability, and wet-sieved water aggregate stability under nine measures. Results indicated that the measurement of SPAM strongly affected soil properties, such as improvements in the fine sand and clay fraction, decreased coarse sand fraction and density, and enhanced content of the larger aggregates ( $>2 \mathrm{~mm})$, organic matter (OM), available nitrogen (AN), available phosphorus (AP), and available potassium (AK). For soil nutrients, applying of Straw/PAM significantly improved the contents of OM/AN, respectively; showing an increasing trend with a dosage rate. Meanwhile, it was shown that SPAM was more effective than treating each individual component on AP and AK improvements. Regard- ing soil structure, application of PAM significantly increased contents of the dry-sieved aggregates and wet-sieved water-stable aggregates, especially aggregates $>2 \mathrm{~mm}$. Straw mulching only improved the content of dry-sieve medium size aggregates. However, when combining SPAM, the straw improved the medium particle size fraction, after which PAM converted a portion of the medium particles into $>2.0 \mathrm{~mm}$ aggregates. Furthermore, the measure proved to be beneficial to land/water ecotone engineering.
\end{abstract}

Keywords: Straw; Polyacrylamide (PAM); Soil stability; Land/water ecotone; Soil restoration

\section{Introduction}

The land/water ecotone (L/WE) is considered to be a buffer zone between terrestrial and aquatic ecosystems. It provides nutrients for plants and microorganisms to protect the water quality of rivers or lakes by infiltrating and retaining phosphorous, nitrogen, suspended solids, and carbon from anthropogenic activities (Yin and Lan, 1995; Wang et al., 2002). Soil is the physical basis of the $\mathrm{L} / \mathrm{WE}$ and can serve as the circulating medium between material and energy. The L/WE's soil stability has a direct impact on the state of the vegetation type and survival, biodiversity, and soil erosion (Holland, 1988). Hence, soil nutrients are important factors that directly affect soil stability (Risser, 1990). According to a previous report (Austin, 2006; Edwards and Bremner, 2006; Wang et al., 2010), aggregate and physical stability are important factors in L/WE soil fertility and stability. Resistance of the aggregate to physical stresses determines soil sensitivity to crusting and erosion (An et al., 2013), germination and rooting of cultivated plants (Frank and Martin, 2013), and the ability of a soil to absorb nutrients ( $\mathrm{Li}$ et al., 2009). This resistance can be achieved through two methods: enhancing soil structure stability and improving soil fertility (Lulseged et al., 2014). Currently, vegetation restoration, straw mulching, and applying structural modifiers constitute effective 

approaches to improving soil structure and soil nutrients, as well as decreasing soil erosion (Stokes et al., 2010).

Straw mulching can be used to improve soil structure and increase soil fertility (Zhu et al., 2007). When straw covers the surface of the soil, decomposition is slow and nutrient leaching by water decreases. Organic matter (OM) formed from straw decomposition slowly enters the soil, which is then involved in crop absorption or formation of soil OM (Huang et al., 2012). Other studies have shown that soil OM with straw mulching increased by 3.9-10.4\% compared to that without straw mulching. Soil available nutrients also increased significantly, the content of potassium in soil $(0-55 \mathrm{~cm})$ increased by $385.4 \%$ compared to soil covered with less straw (Yoong and Newton, 2012). Recent analyses (Liu et al., 2013; Feng et al., 2014) explored the effect of straw mulching on slope runoff and soil erosion. These results revealed that straw mulching can reduce silt content and control soil erosion (can be reduced by $50-80 \%$ ), and its effect is enhanced by an increase in the thickness of the coverage.

Polyacrylamide (PAM), as a soil structural modifier, not only promotes soil aggregate formation and improves soil structure, but decreases surface runoff and nutrient loss (Green et al., 2004; Sepaskhah et al., 2006). A previous report (Long et al., 2002) demonstrated that when the concentration of PAM was $0.03-0.05 \%$, the content of soil water-stable aggregates rose by $29.7-39.8 \%$, and when the application of PAM was $0.25-1.25 \mathrm{~g} / \mathrm{m}^{2}$, the content of water-stable aggregates $(>0.25 \mathrm{~mm})$ increased by an average of $30.20 \%$. Thus, the following processes occurred: loss of soil, decreased rate of soil moisture evaporation, and regulation of soil fertility (Caesar-TonThat et al. 2008). PAM can improve the ability of soil aggregate to absorb nutrients by: firstly, creating an artificial aggregate structure; and secondly, improving the water stability of the soil aggregate structure; and thirdly, this being followed by inhibition of the loss of nutrients by runoff and an improved fertilizer utilization rate (Xia et al., 2012; Flanagan et al., 2002; Hu et al., 2012).

A previous report relied on the engineering of Gonghu Bay (in China) returning from a fishery to its original lake status. The primary objectives of this study were to: (1) investigate the effect of straw and PAM on sediment fertility (e.g., OM, total nitrogen (TN), total phosphorus (TP), total potassium (TK), available nitrogen (AN), available phosphorus (AV), available potassium (AK), and the sediment aggregate and physical stability in a typical land/inland water ecotone; (2) analyze the effect of straw and PAM based on the correlation of $\mathrm{OM}$ and aggregate $(>0.25 \mathrm{~mm})$ content between the other indices; and (3) explore the optimal proportion of straw and PAM. This study may provide a reference for the stability of L/WE sediment ecological restoration.

\section{Materials and methods}

\subsection{Study area}

This study was conducted in the typical L/WE of the Gonghu Wetland in China $\left(122^{\circ} 18^{1}-122^{\circ} 21^{1}\right.$ E and $31^{\circ} 25^{1}-31^{\circ} 27^{1} \mathrm{~N}$ ) (Fig. 1). Gonghu is an important region to the northeast of Taihu Lake, which is located south of Wuxi City and north of Suzhou City. It is not only the hub of communication between Taihu Lake and the Yangtze River, but an important source of Su-xi drinking water and Taihu fish spawning and feeding (Fig. 1).

The study area is situated in the north L/WE demonstration zone of Gonghu Bay, where the fishery was returned to its original lake wetland status (Fig. 2). It has a continental monsoon climate with an annual mean temperature of $16.5^{\circ} \mathrm{C}$ and an annual mean precipitation of $1546 \mathrm{~mm}$. In 2012, repair engineering enhanced the original fish ponds and created a new soil environment. In the eco- tone, the repair mode involved a compound method combining phyto-remediation with straw and PAM.

\subsection{Indoor culture experiment and field implementation}

To explore the optimal proportion of straw and PAM, nine different laboratory experiments were undertaken. The L/WE soil of the Gonghu wetland was sampled for the laboratory experiment and placed in the customized slot, which imitates the L/WE environment (Fig. 3). The experiment consisted of a sunlight-simulated device, water level-regulating valve, and slope-simulated slot. Then these soil were all irradiated under the light intensity of 2500-2800 lx with dark/light cycling of 12:12 h. It is well known that there are many ionsin the water of shallow lake, $0.02 \mathrm{M} \mathrm{KCl}$ solution was used as the simulative lake water. And temperature in the experiments was kept at $25 \pm 3{ }^{\circ} \mathrm{C}$. The nine types of indoor measure sets in the different laboratory experiments were as follows: bare land (BL), $3.0 \mathrm{~g} / \mathrm{kg}$ straw (D1), $1.5 \mathrm{~g} / \mathrm{kg}$ straw (D2), $1.0 \mathrm{~g} / \mathrm{kg}$ PAM(E1), $0.5 \mathrm{~g} / \mathrm{kg}$ PAM (E2), $3.0 \mathrm{~g} / \mathrm{kg}$ straw with $1 \mathrm{~g} / \mathrm{kg}$ PAM (D1E1), $3.0 \mathrm{~g} / \mathrm{kg}$ straw with $0.5 \mathrm{~g} / \mathrm{kg}$ PAM (D1E2), $1.5 \mathrm{~g} / \mathrm{kg}$ straw with $1 \mathrm{~g} / \mathrm{kg}$ PAM (D2E1), and $1.5 \mathrm{~g} / \mathrm{kg}$ straw with $0.5 \mathrm{~g} / \mathrm{kg}$ PAM (D2E2). After culturing for 6 months, soil nutrient and aggregate stability were determined.

In 2014, according to the results of indoor experiments, straw and PAM was applied in the field implementation. For comparison, two methods (with and without straw and PAM) have been implemented in the north L/WE demonstration zone of Gonghu Bay (Fig. 2). The slope was greater than $8^{\circ}$, and the compound modifier was mixed according to the proportion of $3.0 \mathrm{~g} / \mathrm{kg}$ straw with $1.0 \mathrm{~g} / \mathrm{kg}$ PAM. The straw which was $2500 \mathrm{~kg} \mathrm{ha}^{-1}$ of wheat straw (about $70 \%$ surface cover, based on visual estimate) was grounded using a plant grinder and a 200-mesh sieve, and the PAM was anionic with a molecular weight of 2000 (Superfloc A130LMW, marketed by Kemira Co.). Sampling was then performed from the field zone every half month. The nutrient and aggregate stability of the soil sample were determined in the laboratory, and the effects of straw and PAM were analyzed.

\subsection{Soil sample collection and soil physico-chemical properties}

Soil samples were collected twice at each sampling site (zone) and each indoor cultural slot and were collected at a depth of $5.0 \mathrm{~cm}$ by a probe after culturing for 6 months. All soil samples were stored at $4{ }^{\circ} \mathrm{C}$ in the laboratory prior to analysis. The soils for analyses were air-dried and homogenized after removing the visible plant litter, coarse root materials, and stones. Samples were then divided using the quartation method. Half of the total soil was bagged for analysis of aggregate composition, bulk density, and particle size, and the other half was ground through a 100 -mesh sieve to evaluate the $\mathrm{pH}, \mathrm{OM}, \mathrm{TN}$, and TP. All samples were stored prior to the test.

Soil density and porosity were determined using the ring knife method (Niekamp et al., 1984). Particle size distribution was done using a particle size analyzer (Winner2000ZD). Soil $\mathrm{pH}$ values were measured using a $\mathrm{pH}$ meter (soil/water ratio of 1:5). OM was measured employing dichromate oxidation (Nelson and Sommers, 1982). TP was determined by colorimetry after wet digestion utilizing $\mathrm{H}_{2} \mathrm{SO}_{4}$ plus $\mathrm{HClO}_{4}$ (4:1) (Parkinson and Allen, 1975). TN was determined via the Kjeldahl nitrogen method (Bremner and Tabatabai, 1972). TK was determined using the flame atomic absorption method after extraction by $\mathrm{NaOH}$. AN was determined using the alkali diffusion method, available phosphorus (AP) extracted from non-ignited soil using $\mathrm{NaHCO}_{3}$ was determined employing the alkali diffusion method, and AK extracted from nonignited soils using $\mathrm{CH}_{3} \mathrm{COONH}_{4}$ was determined with the flame atomic absorption method (Institute of Soil Science, CAS, 1978). For all samples, triplicate experiments were carried out and the 


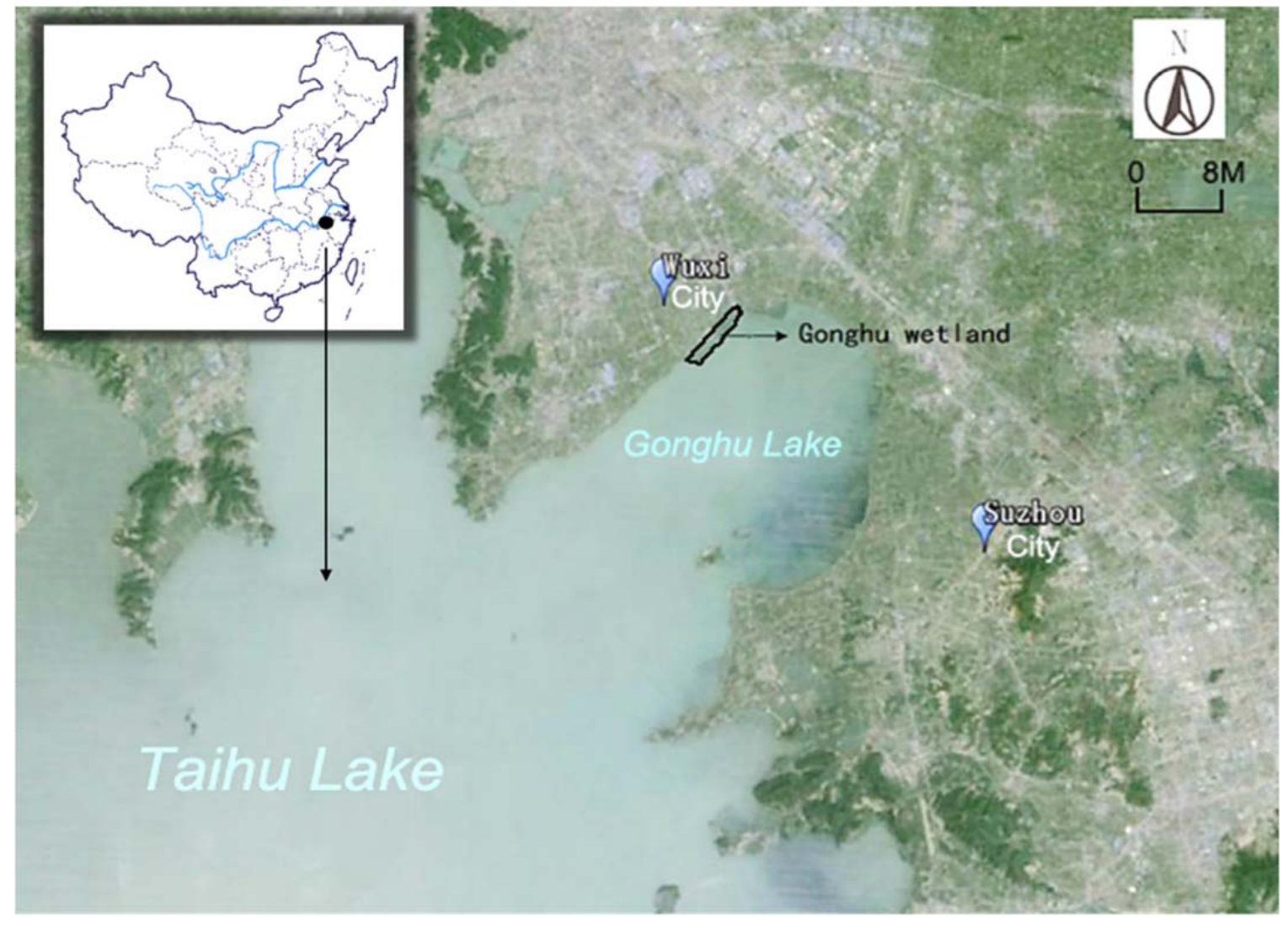

Fig. 1. Location of the Gonghu wetland land/water ecotone.

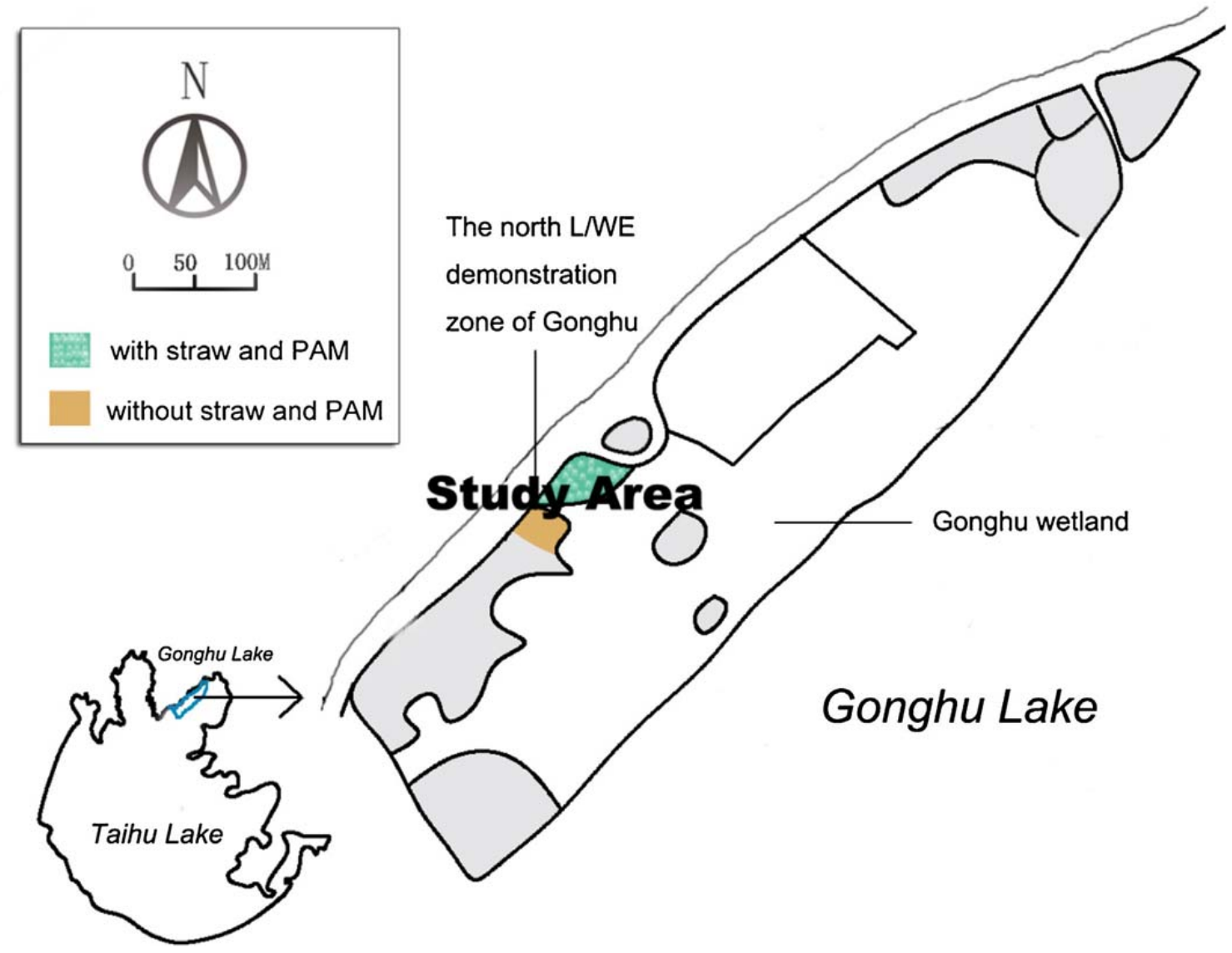

Fig. 2. Overview diagram of the field implement in Gonghu land/water ecotone — a case study area. 


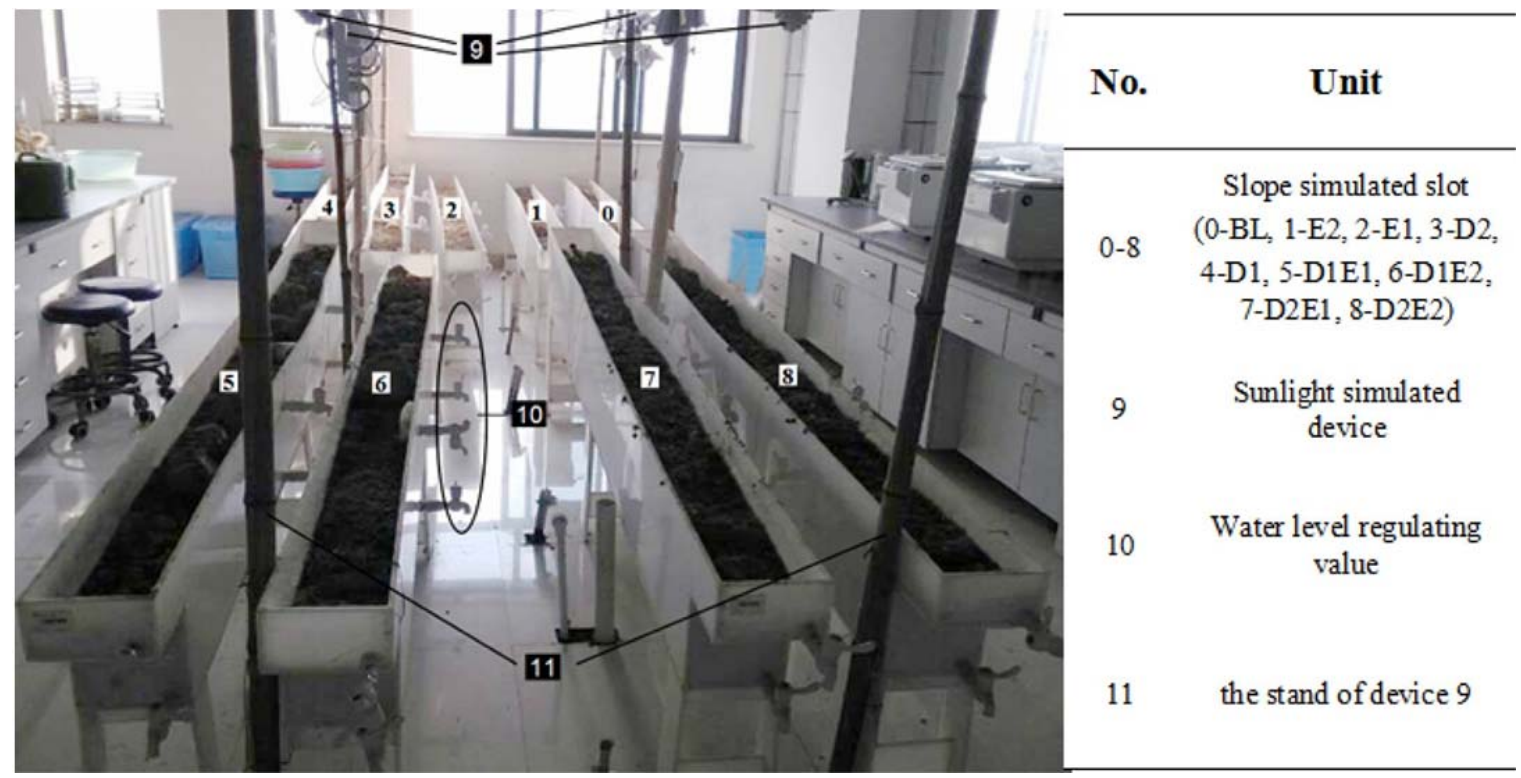

Fig. 3. General view of indoor soil culture experiment device.

Note: BL, bare land; D1, $3 \mathrm{~g} / \mathrm{kg}$ of straw; D2, $1.5 \mathrm{~g} / \mathrm{kg}$ of straw; E1, $1 \mathrm{~g} / \mathrm{kg}$ of PAM; E2, $0.5 \mathrm{~g} / \mathrm{kg}$ of PAM; D1E1, $3 \mathrm{~g} / \mathrm{kg}$ of straw with $1 \mathrm{~g} / \mathrm{kg}$ of PAM;D1E2, $3 \mathrm{~g} / \mathrm{kg}$ of straw with $0.5 \mathrm{~g} / \mathrm{kg}$ of PAM; D2E1, $1.5 \mathrm{~g} / \mathrm{kg}$ of straw with $1 \mathrm{~g} / \mathrm{kg}$ of PAM; D2E2, $1.5 \mathrm{~g} / \mathrm{kg}$ of straw with $0.5 \mathrm{~g} / \mathrm{kg}$ of PAM.

data were expressed as the average of the experiments. The results showed that the standard error deviation in the experiments was within $5 \%$.

\subsection{Soil aggregates and water-stable aggregate stability}

Soil aggregate stability and soil water-stable aggregate stability were determined using the dry-sieving method and the modified Yoder's wet-sieving [WS] method (Zhu, 1982) with a set of 4-, 2-, 1-, 0.5-, and 0.25-mm sieves, respectively. However, the wet-sieve was rapidly immersed in distilled water and oscillated for $3 \mathrm{~min}$ at a displacement of approximately $4 \mathrm{~cm}$ at $37 \mathrm{rev} / \mathrm{min}$. All fractions were weighed after drying at $70^{\circ} \mathrm{C}$. The aggregate stability was expressed as the mean weight diameter (MWD), as follows:

MWD $=\mathrm{w}_{\mathrm{i}} \mathrm{x}_{\mathrm{i}}$ (1) (Zhu, 1982), where $\mathrm{w}_{\mathrm{i}}$ was the mean diameter of size fraction $i$, and $x_{i}$ was the proportion of the size fraction $i$ in relation to the total sample weight. The MWD was performed across all size fractions, including the fraction that passed through the $0.25-\mathrm{mm}$ sieve.

\subsection{Statistical analysis and graphing}

All statistical analyses were conducted using SPSS 11.0 and Excel 2010. Two-way ANOVA was used to test the differences in aggregate distribution among the different sampling zones. Pearson correlation was used to analyze the relationships among all soil stability indices. Different lower case letters indicate significant differences at $\mathrm{p}<0.05$.

\section{Results}

3.1. The effects of the different usage of straw and PAM in indoor experiments

\subsubsection{Distribution of soil particle size for straw and PAM}

Particle size distribution, bulk density, and porosity for different usages of straw and PAM in indoor experiments are presented in Fig. 4 and Table 1. Comparisons among the various usages showed an increase in straw mulching, a decrease in the gravel fraction, an increase in coarse sand, and a decreased influence on fine sand and clay (Fig. 4). Simultaneously, with the increase in PAM content, the gravel and coarse sand fractions decreased, and the fine sand and clay content increased. Subsequently, regarding the repair of soil structure, the effect of PAM was more obvious than that of straw mulching. However, it was worth noting that straw mulching reduced soil bulk density (Table 1). For the D1 and D2 treatment of soil, the average bulk density decreased by $14.9 \%$ (Table 1 ). This was due to straw mulching, which could increase the accumulation of $\mathrm{OM}$, and the degradation of OM could lead to a decrease in soil bulk density.

\subsubsection{Soil nutrients for straw and PAM}

Fig. 5 illustrates the changes in soil nutrients under different amounts of straw mulching, PAM, and their mixtures. Firstly, OM under straw treatment (D1, D2, D1E1, D1E2, D2E1, and D2E2) was significantly higher than that without straw $(\mathrm{E} 1, \mathrm{E} 2)(\mathrm{p}<0.05)$. The content of OM under D1, D1E1, and D1E2 was 42.7\% higher than that of $\mathrm{BL}$ and significantly higher than that of the other measures $(p<0.05)$. Thus, there was a tendency for OM to increase with the usage of straw, but no obvious tendency with PAM. Because compared between D1,D2 (letter ab) and D1E1,D1E2,D2E1,D2E2(letter a, bc), we found add PAM the OM improved less and the same letter show that they have not significant different. Secondly, all of these measures had significant effect on soil AN. No difference in AN between the separate use of straw (D1, D2) and BL was observed, while AN was lower than that with PAM $(p<0.05)$. Generally, increased PAM usage improves the content of AN (e.g. Kay-Shoemake et al., 1998). Thirdly, when comparing D1, D2, E1, and E2, which was the separate use of straw and PAM, no significant differences were observed for the soil AP ( $p>0.05$ ). In contrast, combined treatment with straw and PAM significantly increased the soil AP by $30.9 \%$ compared with BL, especially in D1E1. Consequently, straw combined with PAM application was more effective than were individual treatments on the improvement of AP $(p<0.05)$. Fourthly, generally, the change in AK under the nine measures was similar to that in AP. There was no significant difference between the individual treatments (D1, D2, E1, and E2) and BL ( $>0.05)$. However, for the combined application, the mean content of AK increased by $50.3 \%$ compared with BL $(p<0.05)$. We observed no obvious differences among the combined applications (D1E1, D1E2, 


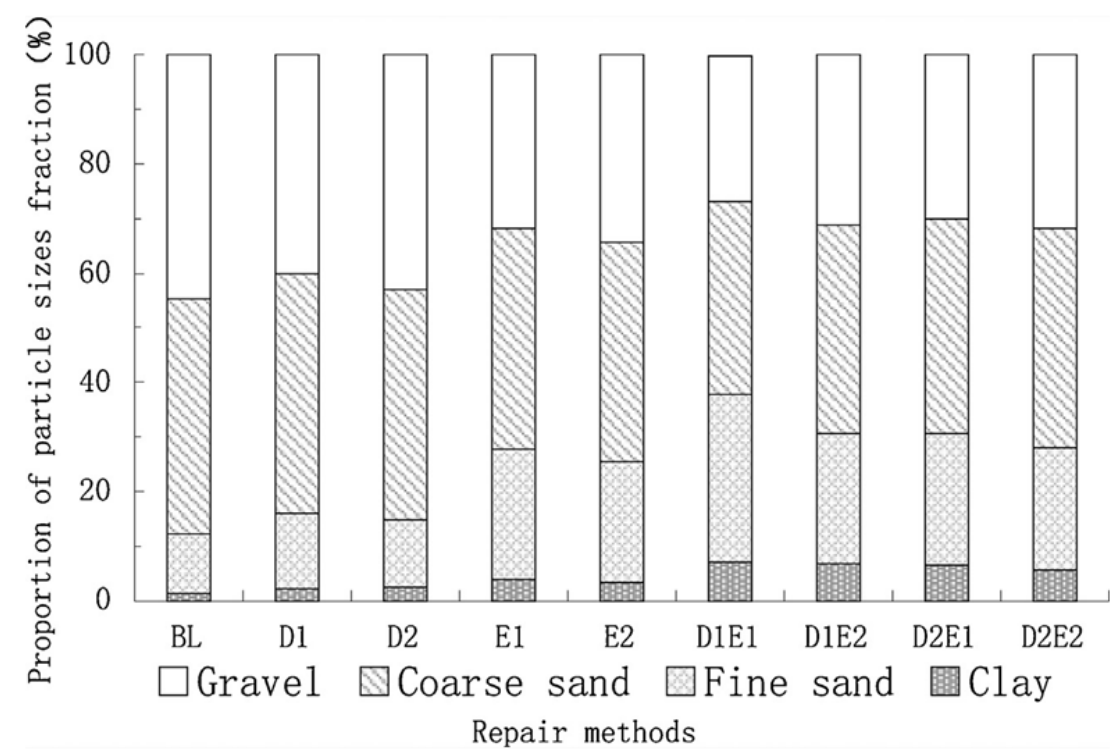

Fig. 4. Soil particle size distribution of nine repair methods in the indoor experiment.

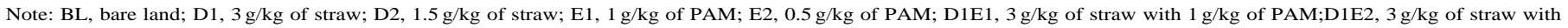
$0.5 \mathrm{~g} / \mathrm{kg}$ of PAM; D2E1, $1.5 \mathrm{~g} / \mathrm{kg}$ of straw with $1 \mathrm{~g} / \mathrm{kg}$ of PAM; D2E2, $1.5 \mathrm{~g} / \mathrm{kg}$ of straw with $0.5 \mathrm{~g} / \mathrm{kg}$ of PAM

Table 1

Soil physical properties of nine repair methods in the indoor experiment.

\begin{tabular}{|c|c|c|c|c|c|c|c|c|c|}
\hline Repair methods & $\mathrm{BL}$ & D1 & D2 & E1 & $\mathrm{E} 2$ & D1E1 & D1E2 & D2E1 & $\mathrm{D} 2 \mathrm{E} 2$ \\
\hline Bulk density $\left(\mathrm{g} / \mathrm{cm}^{3}\right)$ & $1.447 \pm 0.071$ & $1.269 \pm 0.062$ & $1.231 \pm 0.059$ & $1.274 \pm 0.088$ & $1.299 \pm 0.064$ & $1.174 \pm 0.059$ & $1.216 \pm 0.075$ & $1.811 \pm 0.095$ & $1.216 \pm 0.067$ \\
\hline Porosity & $40.4 \pm 2.0$ & $41.0 \pm 2.1$ & $41.3 \pm 2.1$ & $44.1 \pm 1.9$ & $43.1 \pm 2.2$ & $44.5 \pm 3.1$ & $43.6 \pm 1.7$ & $43.3 \pm 1.9$ & $43.9 \pm 2.0$ \\
\hline
\end{tabular}

Table 2

The dry-sieve aggregate component of nine repair methods in the indoor experiment. Means with the same letter in different rows are not significantly different at a 0.05 confidence level. Lower case letters (for example, a-c).

\begin{tabular}{|c|c|c|c|c|c|c|c|}
\hline \multirow[t]{2}{*}{ Repair methods } & \multicolumn{5}{|c|}{ All levels fraction of dry-sieve aggregate(\%) } & \multirow[b]{2}{*}{$<0.25 \mathrm{~mm}$} & \multirow{2}{*}{$\begin{array}{l}\text { MWD(mm) } \\
\text { DS }\end{array}$} \\
\hline & $>4 \mathrm{~mm}$ & $4-2 \mathrm{~mm}$ & $2-1 \mathrm{~mm}$ & $1-0.5 \mathrm{~mm}$ & $0.5-0.25 \mathrm{~mm}$ & & \\
\hline BL & $30.8 \pm 0.4 c$ & $20.8 \pm 0.2 \mathrm{ab}$ & $10.9 \pm 1.9 \mathrm{ac}$ & $17.0 \pm 0.8 b c$ & $10.9 \pm 0.1 \mathrm{~d}$ & $8.9 \pm 0.6 \mathrm{~d}$ & $2.21 \pm 0.24 \mathrm{a}$ \\
\hline D1 & $34.2 \pm 2.0 b c$ & $21.8 \pm 2.1 \mathrm{a}$ & $14.3 \pm 0.8 b$ & $18.0 \pm 0.8 \mathrm{a}$ & $6.9 \pm 0.3 a$ & $6.9 \pm 1.0 \mathrm{c}$ & $2.41 \pm 0.07 \mathrm{a}$ \\
\hline D2 & $33.2 \pm 1.2 \mathrm{bc}$ & $20.7 \pm 0.1 \mathrm{ab}$ & $13.2 \pm 1.2 \mathrm{~b}$ & $18.2 \pm 0.8 \mathrm{ac}$ & $7.2 \pm 2.0 \mathrm{a}$ & $7.9 \pm 2.1 \mathrm{a}$ & $2.33 \pm 0.15 a$ \\
\hline E1 & $48.2 \pm 3.0 \mathrm{a}$ & $19.7 \pm 1.0 \mathrm{ab}$ & $8.8 \pm 0.7 \mathrm{~cd}$ & $11.7 \pm 0.6 c$ & $6.8 \pm 1.3 b$ & $6.0 \pm 1.9 \mathrm{~b}$ & $2.78 \pm 0.22 \mathrm{~d}$ \\
\hline E2 & $47.0 \pm 1.3 \mathrm{a}$ & $18.3 \pm 2.1 \mathrm{bc}$ & $9.5 \pm 0.7 \mathrm{~cd}$ & $13.9 \pm 1.8 \mathrm{c}$ & $7.0 \pm 0.5 b$ & $5.3 \pm 1.4 \mathrm{~b}$ & $2.71 \pm 0.22 c$ \\
\hline D1E1 & $48.4 \pm 3.7 \mathrm{a}$ & $20.5 \pm 2.5 c$ & $7.3 \pm 1.4 b$ & $11.7 \pm 0.3 a$ & $6.7 \pm 0.3 \mathrm{ab}$ & $5.7 \pm 0.6 b c$ & $2.79 \pm 0.31 \mathrm{~d}$ \\
\hline D1E2 & $46.7 \pm 1.5 a$ & $18.6 \pm 0.6 c$ & $9.8 \pm 1.1 \mathrm{bd}$ & $14.8 \pm 0.4 \mathrm{ac}$ & $6.7 \pm 0.1 \mathrm{ac}$ & $5.6 \pm 1.3 \mathrm{bc}$ & $2.72 \pm 0.15 \mathrm{~cd}$ \\
\hline D2E1 & $49.3 \pm 0.1 a$ & $18.3 \pm 0.6 \mathrm{~cd}$ & $7.1 \pm 1.3 b$ & $9.3 \pm 0.2 \mathrm{a}$ & $6.7 \pm 0.5 \mathrm{ab}$ & $8.9 \pm 2.3 \mathrm{ac}$ & $2.74 \pm 0.26 d$ \\
\hline D2E2 & $48.1 \pm 2.2 \mathrm{a}$ & $17.7 \pm 2.1 \mathrm{~cd}$ & $6.5 \pm 0.3 b d$ & $11.6 \pm 0.1 \mathrm{ac}$ & $7.9 \pm 1.4 \mathrm{ac}$ & $8.9 \pm 2.1 \mathrm{ac}$ & $2.69 \pm 0.33 \mathrm{~cd}$ \\
\hline
\end{tabular}

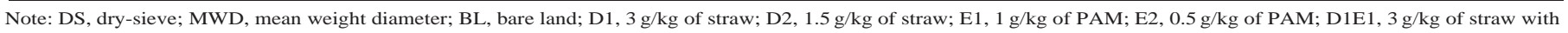
$1 \mathrm{~g} / \mathrm{kg}$ of PAM;D1E2, $3 \mathrm{~g} / \mathrm{kg}$ of straw with $0.5 \mathrm{~g} / \mathrm{kg}$ of PAM; D2E1, $1.5 \mathrm{~g} / \mathrm{kg}$ of straw with $1 \mathrm{~g} / \mathrm{kg}$ of PAM; D2E2, $1.5 \mathrm{~g} / \mathrm{kg}$ of straw with $0.5 \mathrm{~g} / \mathrm{kg}$ of PAM

D2E1, and D2E2). Consequently, from the increase and the significance analysis, we found the combined applications improved the content of AK significantly $(\mathrm{p}<0.05)$. While the usage of $1.5 \mathrm{~g} / \mathrm{kg}$ straw with $0.5 \mathrm{~g} / \mathrm{kg}$ of PAM (D2E2) improved the content of AK best.

\subsubsection{Distribution of soil aggregate fractions for straw and PAM}

The results from the dry-sieving method for soil aggregate stability are shown in Table 2. The distribution of the dry-sieved aggregates via nine measures was variable. The $>4 \mathrm{~mm}$ fraction was $29.2 \%-49.3 \%$, while the $0.50-0.25 \mathrm{~mm}$ and $<0.25 \mathrm{~mm}$ fraction ranged from $6.7-10.0 \%$ to $5.7-12.9 \%$, respectively. The different dosages of PAM and straw had a significant effect on dry-sieved aggregate composition $(\mathrm{P}<0.05)$. The $1-2 \mathrm{~mm} 0.5-1.0 \mathrm{~mm}$ fractions of the D1 and D2 treatments increased, while the usage of straw and median particle size fraction increased. The $>4 \mathrm{~mm}$ fraction of the E1 and E2 treatments increased by $41.75 \%$ and $17.73 \%$, respectively, compared with $\mathrm{LD} 1$. At the same time, the $>4 \mathrm{~mm}$ size fraction of the D1E1 and D1E2 treatments was significantly higher than that of D1 $(\mathrm{P}<0.05)$, and the $>4 \mathrm{~mm}$ size fraction of D2E1 and $\mathrm{D} 2 \mathrm{E} 2$ treatments was significantly higher than that of $\mathrm{D} 2(\mathrm{p}<0.05)$. PAM significantly increased the $>4 \mathrm{~mm}$ dry-sieved aggregate fraction in a dose-dependent manner. Meanwhile, when straw was combined with PAM, straw improved the median particle size fraction, and PAM converted a portion of the median particle size group into $>4 \mathrm{~mm}$ aggregates.

The results for soil water-stable aggregate stability via the WS method are summarized in Table 3. After wet sieving, the nine measurements, the soil aggregate fraction $<0.25 \mathrm{~mm}$ in size was highest (approximately 60\%, Table 3 ) in the indoor soil culture experiment. For the different grades of water-stable aggregates, each aggregate differed for the different dosages of straw and PAM used. There was no significant difference among D1, D2, and B or between DIE1 and D2E1 $(\mathrm{P}>0.05)$. In addition, the $>2 \mathrm{~mm}$ aggregate fraction of the E1 and E2 treatment was significantly higher than that of $\mathrm{BL}(\mathrm{P}<0.05)$, while the $<0.25 \mathrm{~mm}$ aggregate fraction of 

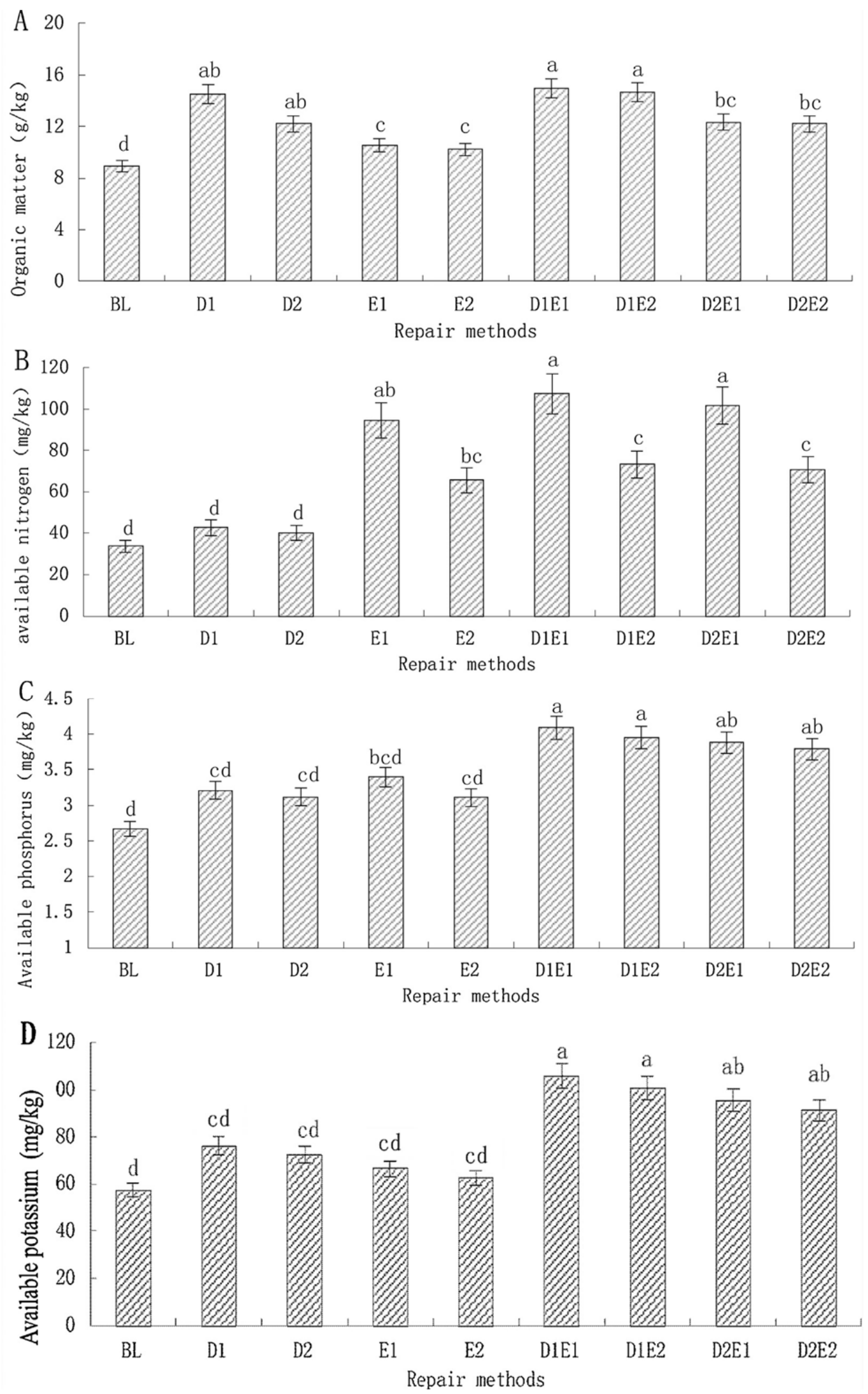

Fig. 5. Soil nutrients of nine repair methods in the indoor experiment.

Note: (A) Organic matter, (B) Available nitrogen, (C) Available phosphorus, and (D) Available potassium. Means with the same letter in different rows are not significantly different at a 0.05 confidence level. Lower case letters (for example, a-c). 
Table 3

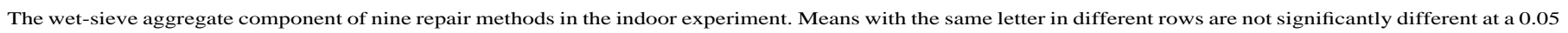
confidence level. Lower case letters (for example, a-c).

\begin{tabular}{|c|c|c|c|c|c|c|c|}
\hline \multirow[t]{2}{*}{ Repair methods } & \multicolumn{5}{|c|}{ All levels fraction of wet-sieve aggregate(\%) } & \multirow[b]{2}{*}{$<0.25 \mathrm{~mm}$} & \multirow{2}{*}{$\begin{array}{l}\text { MWD (mm) } \\
\text { WS }\end{array}$} \\
\hline & $4 \mathrm{~mm}$ & 4-2 mm & $2-1 \mathrm{~mm}$ & $1-0.5 \mathrm{~mm}$ & $0.5-0.25 \mathrm{~mm}$ & & \\
\hline BL & $1.9 \pm 0.1 b$ & $3.4 \pm 1.1 \mathrm{~d}$ & $5.8 \pm 0.4 \mathrm{~d}$ & $9.2 \pm 0.4 b$ & $9.4 \pm 0.2 \mathrm{ab}$ & $69.1 \pm 0.5 a$ & $0.54 \pm 0.03 b$ \\
\hline D1 & $2.7 \pm 0.7 b$ & $3.1 \pm 0.5 \mathrm{~d}$ & $6.0 \pm 0.2 \mathrm{de}$ & $10.3 \pm 0.53 b$ & $10.1 \pm 0.1 \mathrm{a}$ & $68.8 \pm 2.0 \mathrm{a}$ & $0.58 \pm 0.07 b$ \\
\hline D2 & $2.5 \pm 0.2 b$ & $3.5 \pm 0.6 \mathrm{~cd}$ & $5.8 \pm 0.6$ de & $9.3 \pm 0.8 \mathrm{ab}$ & $8.7 \pm 1.3 \mathrm{ab}$ & $69.1 \pm 2.1 \mathrm{a}$ & $0.57 \pm 0.05 b$ \\
\hline E1 & $20.5 \pm 3.2 \mathrm{a}$ & $3.3 \pm 0.4 \mathrm{~b}$ & $5.0 \pm 0.6 \mathrm{e}$ & $11.7 \pm 0.4 \mathrm{a}$ & $11.4 \pm 1.4 \mathrm{c}$ & $48.4 \pm 3.0 \mathrm{~b}$ & $1.25 \pm 0.12 \mathrm{a}$ \\
\hline E2 & $10.6 \pm 0.6 \mathrm{~d}$ & $3.4 \pm 0.7 \mathrm{bc}$ & $3.8 \pm 0.2 \mathrm{e}$ & $12.8 \pm 2.2 \mathrm{a}$ & $10.6 \pm 1.2 \mathrm{bc}$ & $61.2 \pm 1.3 \mathrm{~b}$ & $0.87 \pm 0.10 c$ \\
\hline D1E1 & $24.7 \pm 1.6 \mathrm{e}$ & $3.5 \pm 0.8 b$ & $3.6 \pm 0.5$ eа & $12.8 \pm 1.2 \mathrm{a}$ & $12.4 \pm 0.4 \mathrm{c}$ & $42.9 \pm 3.3 c$ & $1.40 \pm 0.09 \mathrm{ad}$ \\
\hline D1E2 & $11.4 \pm 0.4 c$ & $3.0 \pm 0.1 \mathrm{bc}$ & $4.3 \pm 0.8 \mathrm{ea}$ & $12.3 \pm 0.7 \mathrm{a}$ & $10.3 \pm 2.1 \mathrm{a}$ & $59.3 \pm 2.1 \mathrm{~b}$ & $0.89 \pm 0.11 c$ \\
\hline D2E1 & $22.2 \pm 1.3 \mathrm{e}$ & $3.4 \pm 0.7 \mathrm{~b}$ & $5.8 \pm 0.5 a$ & $13.1 \pm 1.5 \mathrm{a}$ & $11.3 \pm 0.4 \mathrm{c}$ & $44.7 \pm 2.0 \mathrm{c}$ & $1.33 \pm 0.21 \mathrm{ad}$ \\
\hline D2E2 & $11.0 \pm 0.2 \mathrm{e}$ & $3.0 \pm 0.2 b c$ & $4.4 \pm 1.3 a$ & $13.0 \pm 0.7 \mathrm{a}$ & $11.0 \pm 1.3 \mathrm{a}$ & $57.5 \pm 3.7 b c$ & $0.88 \pm 0.07 c$ \\
\hline
\end{tabular}

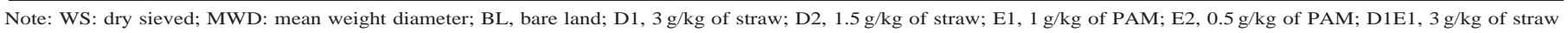
with $1 \mathrm{~g} / \mathrm{kg}$ of PAM;D1E2, $3 \mathrm{~g} / \mathrm{kg}$ of straw with $0.5 \mathrm{~g} / \mathrm{kg}$ of PAM; D2E1, $1.5 \mathrm{~g} / \mathrm{kg}$ of straw with $1 \mathrm{~g} / \mathrm{kg}$ of PAM; D2E2, $1.5 \mathrm{~g} / \mathrm{kg}$ of straw with $0.5 \mathrm{~g} / \mathrm{kg}$ of PAM.

the E1 and E2 treatment declined by $35.39 \%$ and $35.39 \%$, respectively, compared with BL $(p<0.05)$. Moreover, the performance for the trend of the $>4 \mathrm{~mm}$ fraction with $\mathrm{E} 1$ and $\mathrm{E} 2$ treatment was E1>E2. Obviously, along with the increase in PAM dosage, the $>4 \mathrm{~mm}$ aggregate fraction of water stability increased significantly ( $p<0.05$ ). The $<0.25 \mathrm{~mm}$ average fraction of the straw and PAM mixture treatment (D1E1, D1E2, D2E1, and D2E2) was 54.3\%, which fell by $21.3 \%$ compared with BL. Applying PAM treatment to reduce the $<0.25 \mathrm{~mm}$ micro-aggregate fraction proved to be more beneficial than applying PAM treatment $(\mathrm{p}<0.05)$. At the same time, the $>2 \mathrm{~mm}$ water-stable aggregate fraction was significantly higher than without PAM treatment. This confirmed that PAM can gradually polymerize $<0.25 \mathrm{~mm}$ micro-aggregates into $>2 \mathrm{~mm}$ water-stable aggregates. On the whole, straw alone had no significant effect on soil aggregation or water stability. Nevertheless, PAM significantly increased the $>2 \mathrm{~mm}$ water-stable aggregate fraction in a dose-dependent manner $(\mathrm{P}<0.05)$.

\subsubsection{MWD for straw and PAM}

Soil aggregate stability (described as MWD) was affected by different measures, as shown in Fig. 6, Tables 2 and 3. Both in the dry-sieving (DS) and WS experiments, the MWDs of straw and PAM were higher than that of BL (Fig. 6), especially with a high dosage of PAM (E1, D1E1, and D2E2). The MWDs after applying the combined treatments (D1E1, D1E2, D2E1, and D2E2) were greater than those after the individual treatments (E1, E2, D1, and D2) in either the DS or WS experiments. From the significance analysis of MWD, we found that D1,D2 and BL has the similar level in dry-sieve MWD, but with PAM(E1, E2, D1E1, D1E2, D2E1 and D2E2) have significant effect on MWD (Tables 2 and 3). It show that straw have no significant effect on soil structure but PAM. Moreover from the significance analysis of wet-sieve MWD, we found under the action of water straw have significant effect on medium-aggregate and PAM have significant effect on macro-aggregate. To a certain extent, the analysis result proved the mechanism. Similarly, in both DS and WS experiments, the MWDs of E1, D1E1, and D2E2 were higher than those of E2, D1E2, and D2E2. Moreover, there was no difference between D1 and D2. Based on our results, PAM or the combined application of PAM and straw improved soil aggregate stability, and this improvement was associated with an increase in PAM. Straw itself had no effect, even when combined with PAM.

\subsection{The effect of straw and PAM in field implementation}

\subsubsection{The comprehensive quality of field soil}

The soil quality varied significantly after field implementation, as shown in Table 4. Before restoration, the $\mathrm{pH}$ was 5.4, and both the nutrients and available components were poor. The soil structure was loose, the gravel and coarse sand grain fraction were high, and the bulk density was $1.447 \mathrm{~g} / \mathrm{cm}^{3}$. This was not conducive to preserving nutrition and may have led to soil erosion. Comparing straw and PAM treatment to no treatment, the former was more effective in improving soil, while the latter had no effect on such. In the present field implementation study, in the presence of straw and PAM, fine sand and clay in soil increased, the bulk density increased by $24.1 \%$, and the $\mathrm{pH}$ decreased to 4.89 . This change showed that the soil structure and soil buffer capacity improved significantly. OM, TN, TP, and TK increased by $211.3 \%, 274.0 \%, 92.3 \%$, and $5.4 \%$, respectively, compared with before repair. Among them, the content of AN, AP, and AK were 128.48, 25.56, and $184.64 \mathrm{mg} / \mathrm{kg}$, respectively, which all meet Classs III of the Classification Standard of Soil Nutrient Grade in China (Zhang et al., 2007). However, this kind of soil nutrition standardization is lack in the world. For the present results, the application of $3.0 \mathrm{~g} / \mathrm{kg}$ straw combined with $1.0 \mathrm{~g} / \mathrm{kg}$ PAM had a strong influence on L/WE soil.

\subsubsection{The MWD of field soil}

The MWD values of field soil values were determined using the dry-sieve and wet-sieve methods (Table 5) . Of the two stages before and after the repair, the highest MWD values from the drysieve and wet-sieve methods were 2.94 and 1.17, respectively, after treatment with straw and PAM. The MWD with straw and PAM combined treatment was significantly higher than the other MWD values $(p<0.05)$. There were no significant differences between original soil and soil without straw or PAM treatment. Consequently, after field implementation (with straw and PAM), soil aggregate stability and water-stable aggregate stability improved significantly.

\section{Discussion}

\subsection{Effect of straw and PAM on L/WE soil stability}

The aim of this study was to investigate the effects of straw and PAM on L/WE soil based on indoor experiments, which applied straw and PAM separately or combined, and involved as a field implementation analysis. Our results showed that straw and PAM have various effects on soil properties, and these effects relate to their usage.

Considering that the ecosystem of L/WE was abundant, we believe the repair treatment improves not only soil structure, but fertility as well. Based on our results, straw mulching and the application of PAM can repair unstable soil and improve the stability of soil to different degrees. Similar data were reported by Paul et al. (2013). One method is to improve soil fertility, e.g., OM significantly increases with the use of straw $(\mathrm{p}<0.05)$, AN increased with PAM, and straw combined with PAM effectively improved AP and AK (Fig. 5). The other method is to improve the soil structure and the 


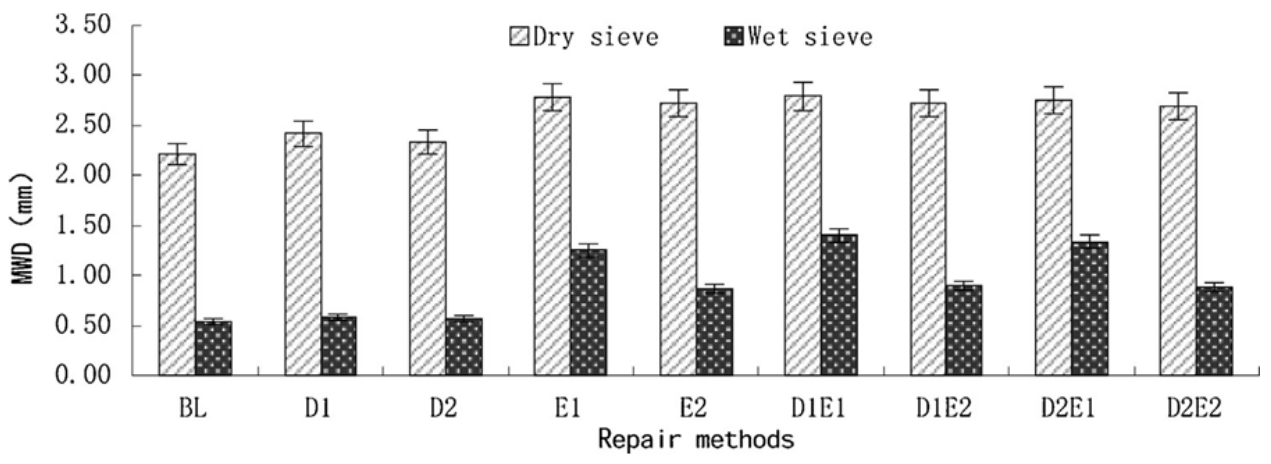

Fig. 6. MWD of nine repair methods in the indoor experiment from the dry sieve and wet sieve. MWD: mean weight diameter.

Note: BL, bare land; D1, $3 \mathrm{~g} / \mathrm{kg}$ of straw; D2, $1.5 \mathrm{~g} / \mathrm{kg}$ of straw; E1, $1 \mathrm{~g} / \mathrm{kg}$ of PAM; E2, $0.5 \mathrm{~g} / \mathrm{kg}$ of PAM; D1E1, $3 \mathrm{~g} / \mathrm{kg}$ of straw with $1 \mathrm{~g} / \mathrm{kg}$ of PAM;D1E2, $3 \mathrm{~g} / \mathrm{kg}$ of straw with $0.5 \mathrm{~g} / \mathrm{kg}$ of PAM; D2E1, $1.5 \mathrm{~g} / \mathrm{kg}$ of straw with $1 \mathrm{~g} / \mathrm{kg}$ of PAM; D2E2, $1.5 \mathrm{~g} / \mathrm{kg}$ of straw with $0.5 \mathrm{~g} / \mathrm{kg}$ of PAM

Table 4

Comprehensive soil quality of different restored measures in the field implement.

\begin{tabular}{|c|c|c|c|}
\hline & \multirow[t]{2}{*}{ Before restoration } & \multirow{2}{*}{$\begin{array}{l}\text { Restored measures } \\
\text { With straw and PAM }\end{array}$} & \multirow[b]{2}{*}{ Without straw and PAM } \\
\hline & & & \\
\hline $\mathrm{pH}$ & $5.4 \pm 0.4$ & $4.9 \pm 0.23$ & $5.3 \pm 0.3$ \\
\hline Gravel(\%) & $44.71 \pm 2.24$ & $18.22 \pm 1.01$ & $37.39 \pm 1.51$ \\
\hline Coarse sand(\%) & $43.04 \pm 2.14$ & $40.15 \pm 1.94$ & $40.17 \pm 2.00$ \\
\hline Fine sand(\%) & $10.89 \pm 0.47$ & $27.32 \pm 1.12$ & $19.97 \pm 0.78$ \\
\hline Clay(\%) & $1.36 \pm 0.05$ & $14.28 \pm 0.67$ & $2.47 \pm 0.08$ \\
\hline Bulk density $\left(\mathrm{g} / \mathrm{cm}^{3}\right)$ & $1.447 \pm 0.062$ & $1.098 \pm 0.045$ & $1.358 \pm 0.067$ \\
\hline $\mathrm{OM}(\mathrm{g} / \mathrm{kg})$ & $9.89 \pm 0.51$ & $30.79 \pm 1.34$ & $13.47 \pm 0.77$ \\
\hline $\mathrm{TN}(\mathrm{g} / \mathrm{kg})$ & $0.50 \pm 0.02$ & $1.87 \pm 0.06$ & $0.66 \pm 0.03$ \\
\hline $\mathrm{TP}(\mathrm{g} / \mathrm{kg})$ & $0.26 \pm 0.01$ & $0.50 \pm 0.02$ & $0.35 \pm 0.02$ \\
\hline $\mathrm{TK}(\mathrm{g} / \mathrm{kg})$ & $16.49 \pm 1.54$ & $17.38 \pm 1.23$ & $16.69 \pm 1.10$ \\
\hline $\mathrm{AN}(\mathrm{mg} / \mathrm{kg})$ & $32.48 \pm 3.21$ & $128.48 \pm 10.33$ & $51.22 \pm 3.87$ \\
\hline $\mathrm{AP}(\mathrm{mg} / \mathrm{kg})$ & $2.57 \pm 0.09$ & $25.56 \pm 1.04$ & $5.29 \pm 0.37$ \\
\hline $\mathrm{AK}(\mathrm{mg} / \mathrm{kg})$ & $56.26 \pm 2.75$ & $184.64 \pm 11.32$ & $68.94 \pm 3.57$ \\
\hline
\end{tabular}

Note: OM, Organic matter; TN, Total nitrogen; TP, Total phosphorus; TK, Total potassium; AN, Available nitrogen; AP, Available phosphorus; AK, Available potassium.

Table 5

MWD of two restored measures in the field implement from the dry sieve and wet sieve. (MWD, mean weight diameter; DS, dry sieve; WS, wet sieve.)

\begin{tabular}{|c|c|c|c|c|}
\hline & & \multirow[t]{2}{*}{ Before restoration } & \multirow{2}{*}{$\begin{array}{l}\text { Restored measures } \\
\text { With straw and PAM }\end{array}$} & \multirow[b]{2}{*}{ Without straw and PAM } \\
\hline & & & & \\
\hline \multirow[t]{2}{*}{$\mathrm{MWD}(\mathrm{mm})$} & DS & $1.89 \pm 0.05$ & $2.94 \pm 0.08$ & $1.94 \pm 0.08$ \\
\hline & WS & $0.45 \pm 0.02$ & $1.17 \pm 0.07$ & $0.55 \pm 0.03$ \\
\hline
\end{tabular}

stability of aggregates and to slow down soil erosion. For example, to repair soil structure, the effect of PAM was more obvious than straw mulching, and the bulk density decreased with increased straw application (Table 1 and Fig. 4).

At the same time, considering that the water level of the L/WE changes frequently, it can lead to the soil alternating between flooded and non-flooded conditions. Thus, the dry- and wet-sieve methods can serve to examine the stability of L/WE soil and waterstable aggregates in the presence of straw and PAM (An et al., 2013). The different dosages of PAM and straw mulching had a significant influence on dry-sieved aggregate composition $(\mathrm{p}<0.05)(\mathrm{e} . \mathrm{g}$ Krauth et al., 2008), and the medium particle size fraction increased with the straw concentration. PAM can significantly increase the $>4 \mathrm{~mm}$ dry sieve aggregate fraction in a dose-dependent manner. Meanwhile, we found that with the combination of straw and PAM, straw can improve the medium particle size fraction and PAM can convert part of the medium particle into $>4 \mathrm{~mm}$ aggregates. Based on this result, we believe that increasing the dosage of the combined application of straw and PAM could improve the soil aggregate stability, and the value of MWD (DS) can confirm this conclusion. However, for the water-stable aggregates, the value of MWD (WS) without repair was significantly less than that of DS without repair. Thus, water stability was especially important regarding L/WE soil stability. Based on this result, applying PAM can gradually polymerize $<0.25 \mathrm{~mm}$ micro-aggregates into $>2 \mathrm{~mm}$ water-stable aggregates, which increases with the dosage of PAM. In addition, the MWD (DS) increased by $178.2 \%$ compared with BL, indicating that PAM improves water stability.

\subsection{Mechanism of straw and PAM on soil improvement}

Most studies have emphasized the effects of individual factors (such as $\mathrm{OM}$, AP, or aggregate) on the variations in soil stability (Sun et al., 2008; Lentz et al., 2000), while all indices were strongly associated with soil stability. The mechanisms and effects of straw and PAM on soil could not be explored based on a single physical or chemical property change (Lulseged et al., 2014). Our results suggested that straw and PAM repaired the degradation of soil to a different degree or improved the stability of soil mainly from two important aspects: enhancing soil structure stability and improving soil fertility. And the modifier of straw and PAM mainly effects the L/WE soil stability by improving the soil structure (Fig. 7).

Straw itself contains various nutrient elements, and the conversion of straw into soil can increase soil nutrients. On the other hand, straw lignin and its protein complex were more difficult to decompose then it residues in the soil, and increase soil's fertility 


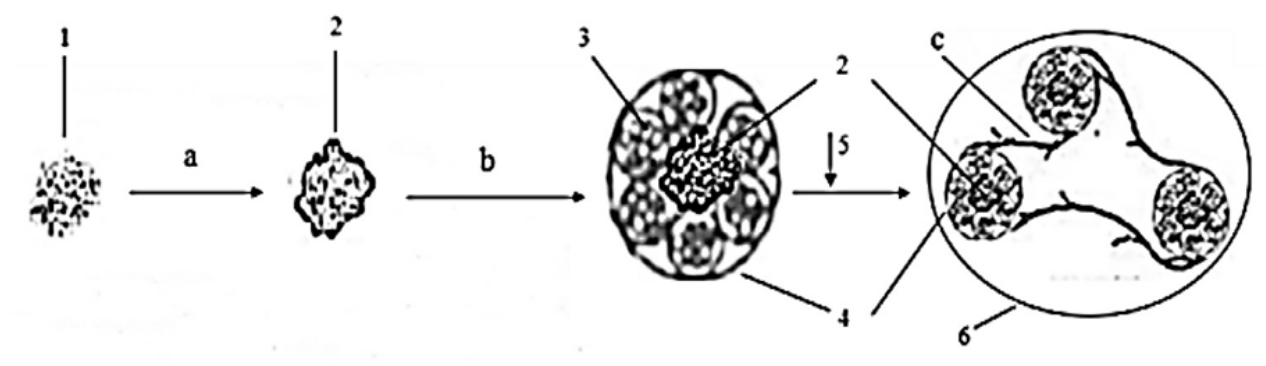

\author{
1-straw; 2-humus; 3 -micro-aggregate; 4-medium aggregate; \\ 5-polyacrylamide; 6-macro-aggregate; 7-application mixed 1 with 5: \\ a-degradation; b-adhesion; c-bridge and adsorption;
}

Fig. 7. The mechanism of effects of straw and PAM on soil structure.

(Wu et al., 2006). We observed that adding straw increased soil OM, AP, and AK. At the same time, the OM of high value could turn into humus which has a larger specific surface and adsorption capacity. Due to these reasons, we found that straw mulching helps format the medium-aggregates by adsorbing the micro-aggregates together, and decrease gravel content, increase coarse sand content, reduce soil bulk density. Moreover, crumb structure was more stable and the soil porous, increasing rainfall infiltration. Based on these changes there was a significant decrease in soil and water loss (Nie et al., 2007).

PAM is one type of polymer, as a soil conditioner structure, that can effectively improve soil structure, increase soil aggregate content, and prevent water soil loss (Caesar-TonThat et al., 2008). There are a large number of hydrophilic groups on the PAM surface; thus, after absorption of clay and coagulation through hydrogen, larger aggregates formed (Green et al., 2004; Wu et al., 2006). Based on indoor experiments, applying PAM to polymerize mediumaggregates $(<0.25 \mathrm{~mm})$ into $>2 \mathrm{~mm}$ macro-aggregates increased water stability (Tables 2 and 3 and Fig. 7). Visible PAM could facilitate the formation of water-stable aggregates by bridge and absorption. Therefore, under the action of water, PAM effectively contributes to fine aggregate condensation into large aggregates and improves soil structure. All specialties of PAM indicated that PAM is particularly suitable for land and water environment (similar to L/WE).

Overall, based on the specific determination of indoor soil samples, we observed an improvement of straw and PAM on L/WE soil. In addition, the results of field implementation confirmed this outcome. With respect to L/WE soil restoration, the positive influence of straw and PAM is important to promote soil nutrients, dry sieve aggregate stability, and wet sieve water-stable aggregate stability. However, based on ANOVA, it has been demonstrated in the present study that the Gonghu Lake L/WE soil stability has increased, enabling the formation of a soil environment suitable for plants and microorganisms in the presence of $3.0 \mathrm{~g} / \mathrm{kg}$ straw with $1.0 \mathrm{~g} / \mathrm{kg}$ PAM. Therefore, the combined application of straw and PAM at dosages of $3.0 \mathrm{~g} / \mathrm{kg}$ and $1.0 \mathrm{~g} / \mathrm{kg}$, respectively, was an excellent eco-engineering measure to improve L/WE soil stability.

\section{Conclusions}

Though the indoor experiment, it was found that the complex which is a mixed application with $3 \mathrm{~g} / \mathrm{kg}$ of straw and $1 \mathrm{~g} / \mathrm{kg}$ of PAM have the best effect on the soil aggregate stability (MWD from 1.97 to 3.00) and soil nutrient and then the compound modifier was implemented in the engineering. Our results showed that mixed straw and PAM can significantly affect soil properties and this effect involves two components. One is that straw and PAM application can increase the available nutrients, which is helpful for plants and microorganisms. The other is that it can improve the structure and aggregate stability of L/WE soil, which can protect against soil erosion and improve the water quality of rivers or lakes through infiltrating and retaining phosphorous and nitrogen. First, the straw increased soil nutrients, and PAM promoted the transformation of effective components. Second, the effect improved with an increase in the dosage of the mixed application, with a recommended dosage of $3 \mathrm{~g} / \mathrm{kg}$ of straw and $1 \mathrm{~g} / \mathrm{kg}$ of PAM, which was confirmed in the indoor experiment and field implementation. PAM also improved the structure of the soil. Overall, in terms of the soil nutrients, applying straw significantly improved the OM content, while the application of PAM significantly improved the content of AN in a dose-dependent manner. Meanwhile, we found that straw combined with PAM was more effective than PAM or straw alone in the improvement of AP and AK. For soil structure, application of PAM significantly increased the content of the dry-sieved and wet-sieved water-stable aggregates, especially for the aggregate fraction larger than $2 \mathrm{~mm}$. The straw mulching only improved the content of dry-sieved median particle size aggregates, but had no significant influence on wet-sieved water-stable aggregates. However, we found that under mulching, straw could turn into humus which has a larger specific surface and adsorption capacity to help format the medium-aggregates by adsorbing the micro-aggregates together. Then by bridge and absorption of PAM, polymerizing the medium-aggregates into $>2 \mathrm{~mm}$ macro-aggregates.

If appropriate, the application of straw and PAM in ecoengineering will mark an important step in increasing sustainability as well as efficient integration into engineering practices and risk management. Moreover, the ecological contribution to L/WE soil stability will be important for slope stabilization and protection.

\section{Acknowlegments}

The research was financially supported by the National Natural Science Foundation (No. 41373027), the China National Major Science and Technology Project for Water pollution Control and Management (2013ZX07101-014, 2012ZX07105-002), Central Public Research Institutes for Basic Scientific Research Projects(2012-YSKY-14). We express our thanks to the members of the project who provided valuable support during the course of soil collection and chemical analysis.

\section{References}

An, S.S., Frédéric, D., Cheng, M., 2013. Revegetation as an efficient means of increasing soil aggregate stability on the Loess Plateau (China). Geoderma 209, 75-85.

Austin, D., 2006. Influence of cation exchange capacity (CEC) in a tidal flow, flood and drain wastewater treatment wetland. Ecol. Eng. 28 (1), 35-43. 
Bremner, J.M., Tabatabai, M.A., 1972. Use of an ammonia electrode for determination of ammonium in Kjeldahl analysis of soils. Commun. Soil Sci. Plant Anal. 3 (2), 159-165.

Caesar-TonThat, T.C., Busscher, W.J., Novak, J.M., 2008. Effects of polyacrylamide and organic matter on microbes associated to soil aggregation of Norfolk loamy sand. Appl. Soil Ecol. 40 (2), 240249.

Edwards, A.P., Bremner, J.M., 2006. Microaggregates in soils. Eur. J. Soil Sci. 18 (1), 64-73.

Feng, Y.Z., Liu, Q., Tan, C.J., Yang, G.H., Qin, X.W., Xiang, Y.Z., 2014. Water and nutrient conservation effects of different tillage treatments in sloping fields. Arid Land Res. Manag. 28 (1), 14-24.

Flanagan, D.C., Chaudhari, K., Norton, L.D., 2002. Polyacrylamide soil amendment effects on runoff and sediment yield on steep slopes: part I. Simulated rainfall conditions. Trans. ASAE 45(5), 13271337.

Frank, G., Martin, F., 2013. Soil aggregate stability related to soil density, root length, and mycorrhiza using site-specific Alnus incana and Melanogaster variegatus s.l. Ecol. Eng. 57, 314-323.

Green, V.S., Stott, D.E., Graveel, J.G., Norton, L.D., 2004. Stability analysis of soil aggregates treated with anionic polyacrylamides of different molecular formulations. Soil Sci. 169, 573-581.

Holland, M.M., 1988. SCOPE/MAB technical consultations on landscape boundaries.

In: Castri, F.D. (Ed.), A New Look at Ecotones: Merging International Projects on Landscape Boundaries, vol. 17. Biology International Special Issue, pp. 47-104.

Hu, X., Liu, L.Y., Li, S.J., Cai, Q.G., Lu, Y.L., Guo, J.R., 2012. Development of soilcrusts under simulated rainfall and crust formation on a Loess soil as influenced by polyacrylamide. Pedosphere 22 (3), 415-424.

Huang, W.R., Bai, Z.H., Hu, Q., Lv, X., Zhuang, G.Q., Xu, S.J., Qi, H.Y.,

Zhang, H.X.,

2012. Effects of cotton straw amendment on soil fertility and microbial communities. Front. Environ. Sci. Eng. 6 (3), 336349.

Institute of Soil Science, CAS, 1978. Soil Physical and Chemical Analysis (in Chinese). Shanghai Science and Technology Press, Shanghai.

Kay-Shoemake, J.L., Watwood, M.E., Lentz, R.D., 1998. Polyacrylamide as an organic nitrogen source for soil micro-organisms with potential effects on inorganic soil nitrogen in agricultural soil. Soil Biochem. 30 (8/9), 1045-1052.

Krauth, D.M., Bouldin, J.L., Green, V.S., Wren, P.S., Baker, W.H., 2008. Evaluation of a polyacrylamide soil additive to reduce agriculturalassociated contamination. Bull. Environ. Contam. Toxicol. 81, 116123.

Lentz, R.D., Sojka, R.E., Ross, C.W., 2000. Polymer charge and molecular weight effects on treated irrigation furrow processes. Int. J. Sediment Res. 15 (1), 17-30.

Li, Y.T., Rouland, C., Benedetti, M., Li, F.B., Pando, A., Lavelle, P., Dai, J., 2009.

Microbial biomass, enzyme and mineralization activity in relation to soil organic $\mathrm{C}, \mathrm{N}$ and $\mathrm{P}$ turnover influenced by acid metal stress. Soil Biol. Biochem. 41, 969-977.

Liu, Y., Gao, M.S., Wu, W., Sikander, K.T., Wen, X.X., Liao, Y.C., 2013. The effects of conservation tillage practices on the soil waterholding capacity of a

non-irrigated apple orchard in the Loess Plateau, China. Soil Tillage Res. 130, 7-12.

Long, M.J., Zhang, H.W., Chen, Z.Q., 2002. Studies on polymeric soil structure amendment III, amelioration to lateritic red soil by polyacrylamide. Chin. J. Soil Sci. 33 (1), 9-13.

Lulseged, T., Quang, B.L., Vlek, Paul L.G., 2014. A landscape planning and management tool for land and water resources management: an example application in northern Ethiopia. Water Resour. Manag. 28 (2), 407-424.
Nelson, D.W., Sommers, L.E., 1982. Total carbon, organic carbon, and organic matter. In: Page, A.L., Miller, R.H., Keeney, D.R. (Eds.), Methods of Soil Analysis: Part II (2nd Edition), Chemical and Microbiological Properties-Agronomy Monograph No. 9. American Soc. Agronomy, Soil Science, America, Madison, WI, USA, pp. 539579.

Nie, J., Zhou, J.M., Wang, H.Y., 2007. Effect of long-term rice straw return on soil glomalin, carbon and nitrogen. Pedosphere 17 (3), 295-302.

Niekamp, A., Unklesbay, K., Unklesbay, N., Ellersieck, M., 1984. Thermal properties of bentonite water dispersions used for modeling foods. J. Food Sci. 49 (1), 28-31.

Parkinson, J.A., Allen, S.E., 1975. A wet oxidation procedure suitable for determination of nitrogen and mineral nutrients in biological material. Commun. Soil Sci. Plant Anal. 6, 1-11.

Paul, B.K., Vanlauwe, B., Ayuke, F., Gassner, A., Hoogmoed, M., Hurisso, T.T., Koala, S., Lelei, D., Ndabamenye, T., Six, J., Pulleman, M.M., 2013. Medium-term impact of tillage and residue management on soil aggregate stability, soil carbon and crop productivity agriculture. Ecosyst. Environ. 164, 14-22.

Risser, P.G., 1990. The ecological importance of land-water ecotones. In: Naiman Décamps, H., Naiman, R.J. (Eds.), The Ecology and Management of Aquatic-Terrestrial Ecotones. Taylor and Francis Group, Lancs, UK, pp. 7-18.

Sepaskhah, A.R., Bazrafshan-JaHromi, A.R., 2006. Controlling runoff and erosion in sloping land with polyscrylamide under a rainfall simulator. Biosyst. Eng. 93 (4), 469-474.

Stokes, A., Sotir, R., Chen, W., Ghestem, M., 2010. Soil bio- and ecoengineering in China: past experience and future priorities. Ecol. Eng. 36, 247-257.

Sun, R.G., Wei, W.S., Ma, M., Li, J.J., Shi, X.J., Zhang, Y.T., Wang, D.Y., 2008. Effects of straw-bentonite-PAM improved material on sandy soil aggregate structure. J. Soil Water Conserv. 25 (2), 162-166.

Wang, W., Wang, D., Yin, C., 2002. A field study on the hydrochemistry land/inland water ecotones with reed domination? Acta Hydrochim. Hydrobiol. 30 (2-3), 117-127.

Wang, L., Yin, C.Q., Wang, W.D., 2010. Sedimentary enzyme kinetics of land/water Ecotones with reed domination. Clean-Soil Air Water 38 (2), 194-201.

Wu, J., Zhu, Z.L., Zheng, J.G., Jiang, X.L., 2006. Influences of straw mulching treatment on soil physical and chemical properties and crop yields. Southwest China J. Agric. Sci. 19 (2), 192-195.

Xia, Q., Yu, H.L., Yu, J., 2012. Effects of different PAM application modes mixed with soil conditioners on rainfall infiltration and soil erosion. Bull. Soil Water Conserv. 11 (3), 23-27.

Yin, C., Lan, Z., 1995. The nutrient retention by ecotone wetlands and their modification for Baiyangdian lake restoration. Water Sci. Technol. 32 (3), 159-167.

Yoong, K.S., Newton, Z.L., 2012. Straw management in a cold semiarid region: impact on soil quality and crop productivity. Field Crops Res. 139, 39-46.

Zhang, F.S., Cui, Z.L., Wang, J.Q., 2007. Current status of soil and plant nutrient management in world and improvement strategies. Bull. Bot., 687-694.

Zhu, H.H., Huang, D.Y., Liu, S.L., Zhu, Q.H., 2007. Effect of ex situ straw incorporation on organic matter content and main physical properties of hilly red soil. Chin. J. Appl. Ecol. 18 (11), 2497-2502.

Zhu, X.M., 1982. Soil and Agriculture in Loess Plateau (in Chinese). Agricultural Press, Beijing. 